\title{
Evaluation of nutrient content and antioxidant, neuritogenic, and neuroprotective activities of upland rice bran oil
}

\author{
Duangkamol Ruen-ngam ${ }^{\mathrm{a}, *}$, Chitti Thawai ${ }^{\mathrm{a}}$, Sujitra Sukonthamut ${ }^{\mathrm{b}}$, Raumjit Nokkoul ${ }^{\mathrm{c}}$, \\ Sarin Tadtong ${ }^{\mathrm{d}}$ \\ a Department of Biology, Faculty of Science, King Mongkut's Institute of Technology Ladkrabang, \\ Bangkok 10520 Thailand \\ b Department of Statistics, Faculty of Science, King Mongkut's Institute of Technology Ladkrabang, \\ Bangkok 10520 Thailand \\ c Department of Agricultural Technology, KMITL PCC, Chumphon 86160 Thailand \\ d Faculty of Pharmacy, Srinakharinwirot University, Nakhon Nayok 26120 Thailand
}

*Corresponding author, e-mail: duangkamol.ru@kmitl.ac.th

Received 27 Oct 2017

Accepted 18 Jun 2018

\begin{abstract}
Upland rice bran is an abundant and valuable antioxidant by-product of rice milling. This study compares the content of $\gamma$-oryzanol, $\gamma$-tocopherol, and phytochemicals in rice bran oil from 4 varieties of upland rice; Dok-kham (DK), Dok-kha (D), Khem-ngen (KN), and Nang-dam (ND); with that of a conventional variety, Khao Dowk Mali 105 (MA). The extraction was done by shaking rice bran in ethanol in $250 \mathrm{ml}$ flask with a rice bran to a solvent ratio of $1: 5(\mathrm{w} / \mathrm{v})$ at $200 \mathrm{rpm}(0.447 \mathrm{~g})$ and $30^{\circ} \mathrm{C}$ in the dark for $30 \mathrm{~min}$. The antioxidant capacity of the extracted oil was evaluated by several methods; DPPH, ferric reducing ability power, and ABTS ${ }^{+}$assays. The colour of upland rice bran oil was dark from its phenolic and flavonoid contents. The highest contents of $\gamma$-oryzanol and $\gamma$-tocopherol were found in the bran oil from KN. The highest phytochemical content was found in the bran oil from DK. DK provided the highest antioxidant activity among the varieties mentioned. The neuroprotective and neuritogenic effects of rice bran extracts were also evaluated. D and KN extracts were the best two neuroprotective and neuritogenic extracts because they had the highest contents of $\gamma$-oryzanol and colour pigments. Thus Thai rice bran oil has the potential to be an excellent food supplement product due to its high antioxidant contents.
\end{abstract}

KEYWORDS: antioxidant activity, phytochemicals

\section{INTRODUCTION}

Rice (Oryza sativa) is a staple food for over half of the world's population. It is well-recognized as an agricultural product exported from Thailand, where the production of rice is up to 20.5 million tons per year ${ }^{1}$. Rice and its bran, a by-product of the milling process, has plenty of nutrients. The bran, in particular, has numerous nutrients. For each rice seed, the weight consisting of its bran is approximately $10-12 \%$ of large amounts of fibre, vitamins, minerals, and other nutritious items that include phenolic compounds, vitamin $\mathrm{E}$ and its associated components, namely, tocols, tocopherol, tocotrienol, and $\gamma$-oryzanol ${ }^{2-5}$. A group of ferulic acid esters of phytosterols called $\gamma$-oryzanol is the main phytochemical component in rice bran oil. $\gamma$ oryzanol can help in the treatment of diseases, such as high cholesterol, cancer, and heart disease ${ }^{2,6}$.

Jasmine rice is a famous, conventional rice variety that grows in lowland areas where flooding is regular. Because of the drought that occurred in 2015 in the middle part of Thailand, it was impossible to grow jasmine rice ${ }^{7}$. Rice varieties that were able to withstand drought were grown in its place, such as Nang Dam, Dok-kham, Dok-kha, and Nangdam. These varieties have different nutritional contents. They are commonly called upland rice, and have originally been cultivated in highland farms, especially in the Southern part of Thailand. Upland rice varieties include Nang Dam and Dok-kham, which are grown in Chumphon province; Khemngoen and Dok-kha, which are grown in Pang-Nga province; and Ku-mueang-luang, which is grown in Surat Thani province ${ }^{8}$.

Cereal bran not only has high nutritional con- 
tent, but specifically it also has abundant antioxidant substances ${ }^{4,8,9}$. Antioxidants retard ageing and prevent Alzeimer's disease as well as cancer ${ }^{10}$. Furthermore, they have the capacity to protect live cells from oxidative damages that occur as a result of the formation of free radicals and reactive oxygen species during most metabolic activities. Beneficial medicinal effects of plant materials are typically due to combinations of phytochemical compounds in the plants that are unique to each plant species. Not long ago, rice husks, bran, and polished rice have been found to have antioxidant capacities ${ }^{4}$. Antioxidant capacity can be measured by several kinds of chemical assays, such as 2,2diphenyl-1-picrylhydrazyl (DPPH), 2,2' -azino-bis(3ethylbenzothiazoline-6-sulphonic acid (ABTS), ferric reducing antioxidant power (FRAP), and oxygen radical absorbance capacity (ORAC) ${ }^{4,9-13}$. In addition to chemical assays, some antioxidant studies have been reported on live animal cells ${ }^{13,17}$; however, more animal research needs to be performed.

Bioactive compounds and their antioxidant capacities, especially the neuroprotective and neuritogenic activities of extracts of upland rice, have yet to be fully explored; hence we decided to conduct this study to evaluate their capacities.

\section{MATERIALS AND METHODS}

\section{Materials}

Four varieties of Thai upland rice, O. sativa (indica) tested in this study were Dok-kham (DK) and Nang-dam (ND) from Chumphon province, Dokkha (D) from Phang-nga province, and Khem-ngen (KN) from Satun province, Thailand. All upland rice varieties were cultivated on the upland in the Southern part of Thailand. Dok-mali (MA) from Suphan Buri province which was used as the control, was cultivated in the middle part of Thailand. All rice samples were collected in October 2014.

\section{Chemical reagents and antioxidant determination}

Standard grade $\gamma$-oryzanol was purchased from Wako Pure Chemical Industries, Ltd, Japan. ABTS ${ }^{+}$, DPPH, 6-hydroxy-2,5,7,8-tetramethylchroman-2carboxylic acid (Trolox), butylated hydroxytoluene (BHT), gallic acid, quercetin, Folin-Ciocalteu reagent, 2,4,6-Tris (2-pyridyl)-1,3,5-triazine (TPTZ) were purchased from Sigma-Aldrich, Germany. Ascorbic acid (vitamin C) was from Fisher Scientific, USA. $\mathrm{FeSO}_{4}, \mathrm{FeCl}_{3}$ solution and potassium persulphate were purchased from Ajax
Finechem Pty Ltd, Australia. Murine embryonal carcinoma cells, P19 ATCC CRL1857, were from the American Type Culture Collection, USA.

\section{Chemical reagents for cell culture and neuronal assays}

Alpha minimal essential medium ( $\alpha$-MEM), newborn calf serum, foetal bovine serum (FBS), and antibiotic-antimycotic solution were purchased from Gibco, USA. Sodium hydrogen carbonate $\left(\mathrm{NaHCO}_{3}\right)$ was from Carlo Erba Reagenti, Italy. All trans-retinoic acid (RA), cytosine-1-D-arabinoside (Ara-C), XTT (sodium 2,3,-bis(2-methoxy-4-nitro-5-sulfophenyl)-5-

[(phenylamino)-carbonyl]-2H-tetrazolium inner salt), and phenazinemethosulphate were purchased from Sigma-Aldrich, USA. Bacteriological grade culture dishes were from Hycon Plastic Inc., USA.

\section{Physical properties and chemical composition}

The colour of rice bran sample was determined with CR-300 colour detector (Minolta, Japan) and was expressed as tristimulus parameters, $L^{*}, a^{*}$, and $b^{*}$ indicating degree of brightness, redness-greenness, and yellowness-blueness, respectively. Chroma $(C)$ indicates colour intensity or saturation $\left(C=\left(\left(a^{*}\right)^{2}+\right.\right.$ $\left.\left.\left(b^{*}\right)^{2}\right)^{1 / 2}\right)$ and Hue angle $15,16\left(H^{\circ}=\tan ^{-1}\left(b^{*} / a^{*}\right)\right)$ were calculated. The chemical composition of the rice bran; protein content, total fat content, moisture, ash and crude fibre are shown in Table $1^{18,19}$. The oil composition was analysed by GC-MS (GC and MS, model G1530 and G2573A, from Agilent). The column used was DB-WAX from J\&W Scientific, USA. Helium gas and ethanol were used as gas carrier and solvent, respectively. The oil composition was listed in Table 2.

\section{Oil preparation}

A rice bran sample was sieved through an $850 \mu \mathrm{m}$ mesh screen (Endecotts Ltd, England) and kept in the dark and cold place until used. A suitable extraction condition was determined previously ${ }^{20}$. The crude rice bran was extracted with ethanol by a maceration method in $250 \mathrm{ml}$ flask at $30^{\circ} \mathrm{C}$ in the dark for $30 \mathrm{~min}$, with rice bran to solvent ratio of $1: 5(\mathrm{w} / \mathrm{v})$ and a circulation rate of $200 \mathrm{rpm}$ $(0.447 \mathrm{~g})$. The debris was removed from the solidliquid mixture by suction through a $0.45 \mu \mathrm{m}$ filter paper. The ethanol was removed from the crude rice bran oil under $5-10$ mbar of vacuum at $40^{\circ} \mathrm{C}$ with a rotary evaporator (Hei-Vap Precision, Heidolph, Germany). Every crude oil sample was kept in a 
Table 1 Colour and chemical contents of five varieties of rice bran.

\begin{tabular}{|c|c|c|c|c|c|}
\hline Parameters & DK & $\mathrm{D}$ & $\mathrm{KN}$ & ND & MA \\
\hline$L^{*}$ & $57.52 \pm 0.22^{\mathrm{e}}$ & $61.41 \pm 0.17^{\mathrm{d}}$ & $68.81 \pm 0.65^{c}$ & $71.47 \pm 0.60^{\mathrm{a}}$ & $70.81 \pm 0.44^{b}$ \\
\hline$a^{*}$ & $15.28 \pm 0.19^{\mathrm{a}}$ & $14.47 \pm 0.11^{\mathrm{b}}$ & $14.47 \pm 0.11^{b}$ & $7.76 \pm 0.22^{\mathrm{e}}$ & $8.82 \pm 0.08^{\mathrm{d}}$ \\
\hline$b^{*}$ & $10.59 \pm 0.14^{c}$ & $12.26 \pm 0.24^{\mathrm{e}}$ & $14.53 \pm 0.25^{\mathrm{a}}$ & $9.95 \pm 0.13^{\mathrm{d}}$ & $13.19 \pm 0.01^{\mathrm{b}}$ \\
\hline C & $18.59 \pm 0.11^{b}$ & $18.96 \pm 0.07^{\mathrm{a}}$ & $18.03 \pm 0.28^{c}$ & $12.62 \pm 0.23^{\mathrm{e}}$ & $15.86 \pm 0.04^{\mathrm{d}}$ \\
\hline$H^{\circ}$ & $1.20 \pm 0.04^{\mathrm{a}}$ & $0.88 \pm 0.04^{b}$ & $0.22 \pm 0.02^{\mathrm{d}}$ & $0.30 \pm 0.02^{c}$ & $0.08 \pm 0.01^{\mathrm{e}}$ \\
\hline \multicolumn{6}{|l|}{ Soxhlet extraction } \\
\hline Oil yield (g/g DW) & $0.27 \pm 0.02^{\mathrm{ax}}$ & $0.17 \pm 0.00^{\mathrm{cx}}$ & $0.17 \pm 0.01^{\mathrm{cx}}$ & $0.19 \pm 0.01^{b x}$ & $0.16 \pm 0.01^{\mathrm{cx}}$ \\
\hline$\gamma$-Oryzanol (mg/g DW) & $8.78 \pm 0.47^{\text {ay }}$ & $4.71 \pm 0.89^{\mathrm{bx}}$ & $7.91 \pm 1.50^{\mathrm{x}}$ & $5.95 \pm 1.37^{\mathrm{bx}}$ & $4.86 \pm 0.20^{\mathrm{bx}}$ \\
\hline \multicolumn{6}{|l|}{ Maceration extraction } \\
\hline Oil yield (g/g DW) & $0.13 \pm 0.00^{\text {by }}$ & $0.12 \pm 0.01^{\text {cy }}$ & $0.14 \pm 0.01^{\text {by }}$ & $0.10 \pm 0.01^{\mathrm{cy}}$ & $0.17 \pm 0.01^{\mathrm{ax}}$ \\
\hline$\gamma$-Oryzanol (mg/g DW) & $6.05 \pm 0.11^{\mathrm{bx}}$ & $5.36 \pm 0.58^{\mathrm{bx}}$ & $7.41 \pm 0.83^{\mathrm{ax}}$ & $2.80 \pm 0.32^{\text {cy }}$ & $4.84 \pm 0.94^{b x}$ \\
\hline Protein $^{\dagger}$ (g/100 g DW) & $13.67 \pm 0.10^{\mathrm{a}}$ & $12.96 \pm 0.02^{b}$ & $13.76 \pm 0.06^{\mathrm{a}}$ & $12.42 \pm 0.13^{b}$ & $12.56 \pm 0.16^{b}$ \\
\hline Total fat $^{\dagger}(\mathrm{g} / 100 \mathrm{~g}$ DW $)$ & $13.63 \pm 0.53^{b}$ & $10.42 \pm 0.10^{c}$ & $10.77 \pm 0.27^{c}$ & $10.99 \pm 0.12^{c}$ & $20.76 \pm 1.47^{\mathrm{a}}$ \\
\hline Moisture $^{*}$ (g/100 g DW) & $11.69 \pm 0.02^{\mathrm{b}}$ & $13.12 \pm 0.13^{\mathrm{a}}$ & $12.89 \pm 0.05^{\mathrm{a}}$ & $10.92 \pm 0.23^{c}$ & $8.63 \pm 0.02^{\mathrm{d}}$ \\
\hline $\mathrm{Ash}^{*}(\mathrm{~g} / 100 \mathrm{~g} \mathrm{DW})$ & $5.76 \pm 0.07^{\mathrm{d}}$ & $8.56 \pm 0.07^{\mathrm{b}}$ & $9.93 \pm 0.02^{\mathrm{a}}$ & $4.99 \pm 0.26^{c}$ & $9.76 \pm 0.02^{\mathrm{a}}$ \\
\hline Crude fibre $^{\dagger}(\mathrm{g} / 100 \mathrm{~g}$ DW) & $7.22 \pm 0.46^{\mathrm{d}}$ & $20.92 \pm 0.07^{\mathrm{a}}$ & $21.18 \pm 0.11^{\mathrm{a}}$ & $7.88 \pm 0.39^{c}$ & $16.32 \pm 0.05^{\mathrm{b}}$ \\
\hline
\end{tabular}

Different superscript letters of $\mathrm{a}, \mathrm{b}$, and $\mathrm{c}$ in the same row indicate significantly different colour values and chemical contents of different varieties at $p<0.05$ by Duncan's New Multiple Range Test.

Different superscript letters of $\mathrm{x}$ and $\mathrm{y}$ in the same row indicate significantly different amounts of $\gamma$-oryzanol extracted by different methods at $p<0.05$ by Duncan's New Multiple Range Test.

$\dagger$ T058 in-house method based on AOAC ${ }^{18}, 991.20,922.06,978.10,962.09$.

ASEANFOODS ${ }^{19}$.

Table 2 Oil composition (\%) of five varieties of rice bran.

\begin{tabular}{lccccc}
\hline Composition & DK & D & KN & ND & MA \\
\hline Pentadecane & - & - & 0.15 & - & - \\
Phenol & 8.31 & 2.04 & 1.69 & 4.99 & 1.36 \\
Nonadecane & 0.77 & - & 0.18 & - & 0.33 \\
Palmitic acid* $^{*}$ & 12.43 & 8.50 & 7.31 & 15.08 & 19.12 \\
Hexadecanoic $^{*}$ & 1.06 & - & 0.27 & 2.33 & 0.11 \\
Linoleic acid $^{18.50}$ & 22.67 & 24.56 & 19.46 & 31.15 \\
Oleic acid & 52.38 & 63.62 & 60.24 & 47.96 & 43.60 \\
Linoleic $^{*}$ & 3.83 & - & 3.42 & 5.92 & 0.46 \\
E-11-H* & 2.72 & - & - & - & - \\
Ethyl oleate & - & - & 2.18 & 4.26 & 2.40 \\
Stearic acid & - & 3.17 & - & - & 1.48 \\
\hline
\end{tabular}

" Palmitic acid (hexadecanoic acid); hexadecanoic acid, ethyl ester; linoleic ethyl ester; E-11-hexadecenoic acid, ethyl ester.

freezer at $-20^{\circ} \mathrm{C}$ until it was used in an assay to determine its antioxidant activity ${ }^{21}$. For comparison of extraction methods, extraction was also performed by using a soxhlet apparatus at $79^{\circ} \mathrm{C}$ for $6 \mathrm{~h}$.

\section{$\boldsymbol{\gamma}$-Oryzanol and $\boldsymbol{\gamma}$-tocopherol determination}

The contents of $\gamma$-oryzanol and $\gamma$-tocopherol were simultaneously determined with a high performance liquid chromatography (HPLC) system (Al- liance 2690, Waters, USA) equipped with a photodiode-array detector ${ }^{20}$. At the start, $30 \mu \mathrm{g} / \mathrm{ml}$ crude oil was prepared in the mobile phase composed of methanol, isopropanol and ethyl acetate in a ratio of 47.5:40:12.5 (v/v). A mixture of $20 \mu \mathrm{l}$ of crude oil and the mobile phase was then injected into a C18 column (ACE, Fortune Scientific Co, Ltd, Thailand) with the mobile phase flow rate of $0.5 \mathrm{ml} / \mathrm{min}$ and analysed at wavelength $330 \mathrm{~nm}$. The chromatogram result was processed and reported with a Shimadzu's LC Solution software program. The $\gamma$-oryzanol concentration was calculated from its area under the peak and compared to the area under the peak of $\gamma$-oryzanol standard of known concentrations ranging from $0.05-50 \mu \mathrm{g} / \mathrm{ml}$.

\section{Phytochemical content}

Total phenolic content (TPC) was determined in triplicate ${ }^{4,14}$. The sample was mixed with a diluted Folin-Ciocalteu reagent at a ratio of $1: 1(\mathrm{v} / \mathrm{v})$ and then incubated for $1 \mathrm{~min}$. The mixture was then added with $10 \% \mathrm{Na}_{2} \mathrm{CO}_{3}$ and incubated for $1 \mathrm{~h}$ in the dark. The absorbance at $734 \mathrm{~nm}$ was recorded with a spectrophotometer (Biomate 3, Thermo Electron Corporation, USA). Serial dilution of gallic acid standard was performed to obtain diluted standard solutions in the range of $5-200 \mu \mathrm{g} / \mathrm{ml}$. TPC was 
expressed as mg of gallic acid equivalent per $1 \mathrm{~g}$ of dried rice bran (mg GAE/g DW).

Total flavanoid content (TFC) was determined by a colorimetric method ${ }^{11}$. One millilitre of $1000 \mu \mathrm{g} / \mathrm{ml}$ rice bran oil was prepared by diluting the oil with methanol. Next, $150 \mu \mathrm{l}$ of $5 \% \mathrm{NaNO}_{2}$ was added and mixed well, followed by subsequent addition and mixing of $150 \mu \mathrm{l}$ of $10 \% \mathrm{AlCl}_{3}$ and $500 \mu \mathrm{l}$ of $5 \% \mathrm{NaCl}$, followed by incubation at room temperature for $40 \mathrm{~min}$. The diluted oil sample was then added to several reagents in sequential order; $150 \mu \mathrm{l}$ of $5 \% \mathrm{NaNO}_{2}, 150 \mu \mathrm{l}$ of $10 \% \mathrm{AlCl}_{3}$ and $500 \mu \mathrm{l}$ of $5 \% \mathrm{NaCl}$. The mixture was then incubated at room temperature for $40 \mathrm{~min}$. The absorbance at $415 \mathrm{~nm}$ was measured. The content of total flavonoids was calculated from the calibration curve of quercetin standard equivalent (mg QE/100 g DW).

\section{DPPH scavenging activity}

DPPH ethanolic solution $(0.2 \mathrm{mM})$ was added to the extracted oil at a ratio of $1: 1(\mathrm{v} / \mathrm{v})$. The wellmixed mixture was kept in the dark for $30 \mathrm{~min}$. The absorbance at $517 \mathrm{~nm}$ of the mixture was measured using a Microplate Reader (EMS Reader MF, Labsystems, Thailand). The concentration of the extract that could inhibit DPPH radicals by $50 \%$ was expressed as $\mathrm{IC}_{50}$. A lower value of $\mathrm{IC}_{50}$ indicates a higher antioxidant activity. The $\mathrm{IC}_{50}$ was compared to antioxidant standards such as ascorbic acid (vitamin C), Trolox, and BHT. Percentage antioxidant inhibition $\mathrm{AI} \%$ was calculated using the following equation:

$$
\mathrm{AI} \%=\frac{1-A_{\text {sample }}}{A_{\text {control }}} \times 100,
$$

where $A_{\text {sample }}$ is the absorbance value of each sample solution, $A_{\text {control }}$ is the absorbance value of the reagent solution, and plotted as a function of concentration to report the antioxidant activity, graphs were reported in Ref. 36.

\section{$\mathrm{ABTS}^{++}$scavenging activity}

To perform the antioxidant activity assay ${ }^{11}$, the ABTS reagent was prepared by stirring $7 \mathrm{mM}$ ABTS in distilled water at $25^{\circ} \mathrm{C}$ and mixed with $2.45 \mathrm{mM}$ potassium persulphate at a ratio of $1: 1(\mathrm{v} / \mathrm{v})$. The mixed reagent was kept at $4{ }^{\circ} \mathrm{C}$ in the dark for $16 \mathrm{~h}$ before use. The oil sample was mixed with such reagent at a ratio of 1:50 (v/v), and the absorbance at $734 \mathrm{~nm}$ was recorded. The results of antioxidant activity of crude oil are reported in the form of AI\%, including $\mathrm{IC}_{50}$ and TEAC values. TEAC value was the Trolox concentration that was equivalent in AI\% to that of the crude oil; it was calculated based on a Trolox standard curve $\left(R^{2}=0.997\right)(\mathrm{mg}$ TEAC $/ g$ DW).

\section{FRAP assay}

Ferric reducing ability assay ${ }^{22}$ was used to analyse the ability of antioxidant compound to transfer electrons and change ferric tripyridyltriazine $\left(\mathrm{Fe}^{3+}\left[(\mathrm{TPTZ})_{2}\right]^{3+}\right)$ to ferrous tripyridyltriazine $\left(\mathrm{Fe}^{2+}\left[(\mathrm{TPTZ})_{2}\right]^{2+}\right)$. An FRAP reagent was prepared by mixing $300 \mathrm{mM}$ acetate buffer $(\mathrm{pH}$ 3.6) with $20 \mathrm{mM} \mathrm{FeCl}_{3}$ and $10 \mathrm{mM} \mathrm{TPTZ}$ solution at a ratio of $10: 1: 1(\mathrm{v} / \mathrm{v})$ and incubating the mixture at $37^{\circ} \mathrm{C}$ for $30 \mathrm{~min}$. The oil sample in ethanol was added to FRAP reagent at a ratio $1: 3(\mathrm{v} / \mathrm{v})$ and incubated for $5 \mathrm{~min}$ before measuring of its absorbance at $595 \mathrm{~nm}$. FRAP value was the concentration of Trolox or $\mathrm{FeSO}_{4}$ that was equivalent in the $\mathrm{AI} \%$ to that of the crude oil. Hence it was expressed as Trolox or $\mathrm{FeSO}_{4}$ equivalent antioxidant capacity (mg TEAC/g DW and $\mathrm{mM} \mathrm{FeSO}_{4} / \mathrm{g} \mathrm{DW}$ ).

\section{Neuronal differentiation}

P19 cells at the exponential growth stage were dissociated into single cells ${ }^{17}$ and seeded on a 100$\mathrm{mm}$ bacteriological culture dish in P19IM under a $5 \% \mathrm{CO}_{2}$ humidified atmosphere at $37^{\circ} \mathrm{C}$ for 4 days to allow the cells to form large aggregates. After 4 days of RA treatment, aggregates were dissociated into single cells, re-plated on poly-L-lysinepre-coated multi-well plates at $7 \times 10^{4}$ cells $/ \mathrm{ml}$ in P19SM and incubated for $24 \mathrm{~h}$. Cytosine-1- $\beta$-Darabinoside $(10 \mu \mathrm{M})$ was added on the following day after plating and the medium was changed every 2-3 days. The differentiated neuronal cells, P19 derived-neurons, and cholinergic neurons were used in a neuronal viability assay after day 14 of the differentiation process.

\section{Neuronal viability assay}

The assay ${ }^{17}$ was performed in triplicate. DMSO solutions of the samples were diluted with P19SM in the presence of $10 \mu \mathrm{M}$ Ara-C to obtain solutions at the concentrations in the range of $1-10000 \mathrm{ng} / \mathrm{ml}$ and added to the culture plates. P19SM plus $10 \mu \mathrm{M}$ Ara-C were added to the control wells. The cells were then incubated for $18 \mathrm{~h}$ at $37^{\circ} \mathrm{C}$. Then $150 \mu \mathrm{l}$ of the medium was removed, and $50 \mu 1$ of XTT solution $(1 \mathrm{mg} / \mathrm{ml} \mathrm{XTT} \mathrm{in} \alpha$-MEM and $25 \mu \mathrm{M}$ phenazine methosulfate) was added. After the mixture was incubated at $37^{\circ} \mathrm{C}$ for $4 \mathrm{~h}, 100 \mu \mathrm{l}$ of PBS was added. 
The absorbance at $450 \mathrm{~nm}$ of the mixture was determined with a microplate reader. The results were expressed as mean $\pm \operatorname{SD}(n=3)$, with medium only as a control representing $100 \%$ cell viability. The sample at the concentration that enhanced the survival of cultured neurons compared to that in the control was further investigated for its neuritogenicity and neuroprotective effect.

\section{Neuroprotective assay by serum deprivation method}

The assays were carried out on P19 derived-neurons cultured in a 96-well plate and performed in tripicates. Serum deprivation method ${ }^{23}$ was used. The DMSO solution of the samples, diluted with P19SM plus $10 \mu \mathrm{M}$ Ara-C, and $\alpha$-MEM supplemented with $10 \mu \mathrm{M}$ Ara-C, and 1\% antibiotics-antimycotic solution without FBS were added to give a final concentration of the sample that enhanced survival of cultured neurons more than that of the control. DMSO was added to the cultures at $0.5 \%$. P19SM plus $10 \mu \mathrm{M}$ Ara-C was added to the control wells. $\alpha$-MEM supplemented with $10 \mu \mathrm{M}$ Ara-C, and $1 \%$ antibiotics-antimycotic solution without FBS was used to create the oxidative stress condition. Quercetin at $1 \mathrm{nM}$ was used as a positive control. The cells were incubated for $18 \mathrm{~h}$ at $37^{\circ} \mathrm{C}$. Cell viability was assayed by the XTT reduction method. The data are expressed as mean $\pm \operatorname{SD}(n=3)$, with the medium as a control representing $100 \%$ cell viability.

\section{Neuritogenicity assay}

The assay was carried out together with P19derived-neurons cultured in a 6-well plate ${ }^{17}$. After 14 days of differentiation process, P19SM plus $10 \mu \mathrm{M}$ Ara-C were removed and DMSO solution of the extracts diluted with P19SM plus $10 \mu \mathrm{M}$ Ara$\mathrm{C}$ were added to give the final concentration of the sample at concentration that enhanced survival of cultured neurons more than that of the control, a DMSO (0.5\%) was added to the cultures. P19SM plus $10 \mu \mathrm{M}$ Ara-C was added into control wells. Quercetin at $1 \mathrm{nM}$ was used as a positive control. The cells were incubated for $18 \mathrm{~h}$ at $37^{\circ} \mathrm{C}$. The morphology under a phase-contrast microscope was observed. The appearance of P19-derived neurons was compared to that of the controls and measured for the length and number of neurites. Average length and number of neurites of 30 neurons from the assay were measured.

\section{Statistical analysis}

Means and standard deviations of oil yield and antioxidant activity of triplicates were reported. The statistical analysis for comparison of the means at 95\% confidence limit $(p<0.05)$ was performed by one-way ANOVA and Duncan's multiple range test with SPSS 22.0. Neuroprotective and neuritogenic activity assays were statistical analysed by student's $t$-test at 95\% confidence limit $(p<0.05)$.

\section{RESULTS AND DISCUSSION}

\section{Physical properties and chemical contents}

The upland rice brans were remarkably darker than the conventional rice bran (MA), with the exception of the bran from ND rice, as shown in the second row ( $a^{*}$ value) of Table 1 . ND has the highest value of lightness compared to the other varieties. In addition, the Southern rice variety appeared to be redder than the rice variety from the central region of Thailand (MA) (lower $a^{*}$ value). The chroma $(C)$ value of upland rice bran was significantly higher than that of MA. The rice bran contains phytochemicals such as phenolics, which are especially abundant in the upland rice bran and which cause the dark red appearance. A previous research study has shown that physical traits of a bran such as colour are correlated to its phytochemical content ${ }^{16,25}$. Specifically, the genotypes of the purple bran were correlated with significantly higher TFC, TPC and oxygen radical absorbance capacity than those of the red rice bran. The colour parameters were related to the colour of various chemical contents. $C$ and $H^{\circ}$ represented phenolic content, $L^{*}$ and $a^{*}$ were mainly attributed to flavonoid contents ${ }^{16,25}$. The values of the parameters reported in our study were found to have the same correlation as mentioned above. Furthermore, the amount of $\gamma$-oryzanol was correlated with the yellow parameter, $b^{*}$, which was at the highest levels for $\mathrm{KN}$ and MA compared to those of the other rice varieties (Table 1).

\section{Comparison of the extraction methods}

This section presents the rationale for choosing the use of maceration method instead of conventional soxhlet extraction method to extract rice bran oil. Initially, rice bran oil was preliminary extracted by both methods; conventional soxhlet and maceration methods. The soxhlet method gave significantly higher oil yield than the maceration method (Table 1), and the results follow the same trends for all varieties except for MA. The effect of different extraction methods on the amount of $\gamma$-oryzanol, 
a type of antioxidant compound, was found to be significantly different for DK and ND rice varieties, whereas the effect was not significantly different for $\mathrm{D}, \mathrm{KN}$, and MA (Table 1). The elevated extraction temperature at ethanolic boiling point of the soxhlet method did not affect $\gamma$-oryzanol yield of $\mathrm{D}, \mathrm{KN}$ and MA, whereas it increased the $\gamma$-oryzanol yield of DK and ND. This was because of the significantly higher content of crude fibre in $\mathrm{D}, \mathrm{KN}$ and MA compared with those in DK and ND, as shown in the crude fibre content in Table 1. The extra heat might soften the crude fibre ${ }^{26,27}$ but there was still some trapped $\gamma$-oryzanol-rich oil inside the crude fibre structure that could not penetrate through it. The results also agreed with that of antioxidant activity by DPPH and ABTS assays that showed a higher activity when maceration was used as the extraction method than when soxhlet was used ${ }^{36}$. However, this result was in contrast with the result from the FRAP assay that showed higher AI\% achieved by soxhlet extraction than that achieved by maceration. Apart from $\gamma$ oryzanol, other types of antioxidant compounds such as phenolics and flavonoids, which are known to be heat resistant compounds, were found to have higher yields from soxhlet extraction for all varieties $^{28}$. However, many types of antioxidants that are heat intolerant have not been explored before; hence, a gentler extraction method, maceration by ethanol, was the extraction method of choice in this study. Indeed, ethanolic extraction by maceration has been regarded as an environment-friendly method of extraction ${ }^{13,20,29,30}$.

\section{Total oil, $\boldsymbol{\gamma}$-oryzanol, tocopherol and phytochemical contents}

The oil yield from the bran of conventional rice variety (MA) was the highest when the oil was extracted with the maceration method, compared to the yields from the bran of the upland rice varieties (Table 3). The MA oil appeared to be clear and yellowish, whereas the upland rice bran oil was yellowish to dark brownish. The darkest oil was the oil from DK. At the completion of the maceration method, two phases of products were obtained: the oil phase and a solid phase caused by precipitation into red to brown crystals. The exception was ND in which maceration did not yield any precipitation. Red crystals were similarly found in other studies $^{6,29}$. The red crystals contained components of tocopherol (vitamin E) and $\gamma$-oryzanol. Some research studies have claimed that the red colour is due to a group of phenolics and flavonoids ${ }^{25}$.

Tocopherol was found simultaneously with $\gamma$ - oryzanol by the HPLC method. The peak of $\gamma$ oryzanol appeared at the retention times of 5.6 and $6 \mathrm{~min}$, the peak of $\gamma$-tocopherol showed up at the retention times of $3.35,3.51,3.85$, and $4.27 \mathrm{~min}$, whereas no peak was found for $\alpha$-tocopherol. KN provided the greatest amount of $\gamma$-oryzanol of $7.41 \pm 0.83 \mathrm{mg} / \mathrm{g}$ DW at a significance level of $95 \%$ $(p<0.05)$ compared to those provided by other types of rice bran, followed by DK, D, MA and ND (Table 3). This might be effects of the cultivation area and the cultivation method. The $\gamma$-oryzanol content was similar to that previously reported ${ }^{4}$ in rice cultivated in a low water level zone in the Northeast part of the country.

$\gamma$-tocopherol was present at the highest percentage in MA and KN at a significance level of 95\%, followed by D and ND (Table 3). Surprisingly, $\gamma$ tocopherol was not found in DK, which contradicts results from Chotimarkorn ${ }^{29}$ and Ushio ${ }^{35}$. This might be because the rice was grown in different cultivation areas. For total phenolic content, DK had the greatest amount at a significant level of $95 \%$ at around $6.44 \pm 0.20 \mathrm{mg} \mathrm{GAE} / \mathrm{g} \mathrm{DW}$, followed by D and MA, and then KN and ND (Table 3). The DK oil had the highest TFC, around $13.32 \pm 0.52 \mathrm{mg} \mathrm{QE} / \mathrm{g}$ DW, compared to MA, KN, ND and D (Table 3). This study reports a higher TFC content in the oil from upland rice compared to that reported in Ref. 29; nevertheless, the difference might be due to the presence of catechin in their report.

In performing the antioxidant assay, both the oil and red crystal extraction products were used in the assay. Hence the high activity found might come from both the oil and the crystals. The red crystals, products from the extraction process that came out with the oil, were suspected to be from the brownish or reddish skin of the varieties of upland rice and contained $\gamma$-oryzanol and tocopherol; however, even though the skin of MA was white, it also contained high levels of such compounds. Nevertheless, the oil from MA had lower antioxidant activity than the extraction products from the varieties of upland rice. In addition, the colour of the rice bran, the yellow parameter $\left(b^{*}\right)$, may reveal the $\gamma$-oryzanol content in the rice bran oil.

\section{Antioxidant capacity}

All the varieties had AI\% values greater than $50 \%$, as indicated by the DPPH assay, whereas in the case of the ABTS assay, only DK had the highest AI\%, by more than $50 \%$, therefore IC $_{50}$ for all varieties by DPPH assay can be calculated. Among all the varieties, DK demonstrated the highest $\mathrm{AI} \%$ when 
Table 3 Quantitative and qualitative analyses of the extracts from five varieties using maceration method.

\begin{tabular}{|c|c|c|c|c|c|}
\hline Parameters & DK & $\mathrm{D}$ & $\mathrm{KN}$ & ND & MA \\
\hline$\gamma$-Oryzanol (mg/g DW) & $6.05 \pm 0.11^{\mathrm{b}}$ & $5.36 \pm 0.58^{\mathrm{b}}$ & $7.41 \pm 0.83^{\mathrm{a}}$ & $2.80 \pm 0.32^{c}$ & $4.84 \pm 0.94^{b}$ \\
\hline$\gamma$-Tocopherol (mg/g DW) & - & $0.03 \pm 0.00^{\mathrm{b}}$ & $0.06 \pm 0.03^{\mathrm{ab}}$ & $0.03 \pm 0.06^{\mathrm{b}}$ & $0.12 \pm 0.04^{\mathrm{a}}$ \\
\hline TPC (mg GAE/g DW) & $6.44 \pm 0.20^{\mathrm{a}}$ & $3.21 \pm 0.08^{\mathrm{b}}$ & $2.49 \pm 0.10^{c}$ & $2.09 \pm 0.10^{\mathrm{d}}$ & $3.19 \pm 0.19^{b}$ \\
\hline TFC (mg QE/g DW) & $13.34 \pm 0.52^{\mathrm{a}}$ & $3.79 \pm 0.49^{\mathrm{e}}$ & $5.84 \pm 0.22^{\mathrm{c}}$ & $4.70 \pm 0.14^{\mathrm{d}}$ & $9.71 \pm 0.08^{b}$ \\
\hline DPPH $\left(\mathrm{IC}_{50}, \mathrm{mg} / \mathrm{ml}\right)$ & $0.11 \pm 0.01^{\mathrm{a}}$ & $0.28 \pm 0.03^{b}$ & $1.17 \pm 0.01^{\mathrm{c}}$ & $4.16 \pm 0.01^{\mathrm{e}}$ & $3.42 \pm 0.04^{d}$ \\
\hline ABTS (mg TEAC/g DW)) & $34.94 \pm 1.26^{\mathrm{a}}$ & $8.36 \pm 1.04^{\mathrm{b}}$ & $7.23 \pm 0.27^{\mathrm{b}}$ & $3.73 \pm 0.19^{c}$ & $7.73 \pm 0.28^{b}$ \\
\hline FRAP (mg TEAC/g DW) & $5.16 \pm 0.35^{\mathrm{a}}$ & $4.93 \pm 0.38^{\mathrm{a}}$ & $2.73 \pm 0.15^{\mathrm{b}}$ & $0.91 \pm 0.03^{d}$ & $1.77 \pm 0.12^{\mathrm{c}}$ \\
\hline FRAP (mM FeSO $4 / g$ DW) & $53.13 \pm 3.51^{\mathrm{a}}$ & $50.69 \pm 3.85^{\mathrm{a}}$ & $28.61 \pm 1.53^{b}$ & $9.87 \pm 0.31^{\mathrm{d}}$ & $19.04 \pm 1.20^{c}$ \\
\hline FRAP $\left(\mathrm{IC}_{50}, \mathrm{mM} \mathrm{FeSO}_{4} / \mathrm{g} \mathrm{DW}\right)$ & 0.25 & 0.13 & 0.50 & 1.20 & 1.20 \\
\hline
\end{tabular}

Different superscript letters of $a, b$, and $c$ in the same row indicate significantly different amount of quantitative and qualitative values of different varieties at $p<0.05$ by Duncan's New Multiple Range Test.

compared to other varieties, with $\mathrm{IC}_{50} \mathrm{DPPH}$ of $0.11 \pm 0.01 \mathrm{mg} / \mathrm{ml}$ at a significant level of $95 \%$ (Table 3). Furthermore, the rice bran oil from DK had an AI\% of around 31.1 fold higher than MA, which had the same level as upland rice ND. $\mathrm{DK}$ and $\mathrm{D}$ were in the same range as vitamin $\mathrm{C}$, an antioxidant standard, with $\mathrm{IC}_{50} \mathrm{DPPH}$ of $0.01 \pm 0.00 \mathrm{mg} / \mathrm{ml}$. On the other hand, Trolox $(0.02 \pm 0.00 \mathrm{mg} / \mathrm{ml})$ and BHT $(0.13 \pm 0.01 \mathrm{mg} / \mathrm{ml})$ had higher antioxidant capacities than the other rice varieties at a significant level of $95 \%$. These results concur with the previously reported results which showed that rice bran has the highest antioxidant activity ${ }^{4}$, higher than BHT; however, it had lower antioxidant activity than ascorbic acid and Trolox.

The AI\% revealed by the ABTS assays for all the rice varieties was less than $50 \%$, except for DK. According to the TEAC results shown in Table 3, among the oils studied, DK had the highest amount of TEAC at a significant level of $95 \%$, and it was detected at about $34.9 \pm 1.3 \mathrm{mg}$ TEAC/g DW. Furthermore, the content extracted via the soxhlet method was higher in oil by $66 \%$. Because of its type and cultivation area, the DK variety had greater antioxidant capacity. Additionally, DK has antioxidant capacity in the same range with TEAC as those of Sudu Heeneti, Masuran, Goda Heeneti, and Dik Wee, Sri Lankan traditional red rice ${ }^{27}$.

FRAP was also used to analyse antioxidant activity. Results were consistent with those from the ABTS assay that no variety of rice can reach an antioxidant inhibition level of $50 \%$; hence results were reported in the form of $\mathrm{mg}$ TEAC/g DW and $\mathrm{mM}$ $\mathrm{FeSO}_{4} / \mathrm{g}$ DW. DK and D fell within the same range of FRAP values, and received highest FRAP values when compared to the others (Table 3). Antioxidant capacity via FRAP has been found ${ }^{4}$ to be in the range of 27.5-32.2 $\mu \mathrm{mol} \mathrm{FeSO} / \mathrm{g}$, whereas in this study a wider range of 9.87-53.13 $\mu \mathrm{mol} \mathrm{FeSO}_{4} / g$ crude oil was obtained. These differences might be due to the differences in varieties and cultivation areas.

\section{Comparison of rice bran varieties}

The most recent research data and the results from this study are shown in Table 3 and Table 4. The rice bran having the highest antioxidant content is cultivated in Asia, mostly in Thailand. All the research focused on TPC which showed that the maximum content level was related to the degree of pigment in the rice ${ }^{33}$. The second highest level of TPC was obtained from the Korean rice bran ${ }^{31}$ and DK rice bran, and the third one was obtained from the $\mathrm{D}$ and MA varieties, as well as Khao Pathumthani $60^{29}$ and the bran from $\operatorname{Iran}^{29}$. This study reports a higher level of TPC as compared to the others ${ }^{4,29}$, while it was in the same range as that in the Iranian rice $^{24}$. Total flavonoid content had the highest value compared to other reports (Table 4). The highest amount of $\gamma$-oryzanol content was found in $\mathrm{KN}$, whereas the DK and MA were found to have lesser amount of $\gamma$-oryzanol ${ }^{4}$. The same variety of MA was found in Refs. 4, 29; however, the yield from Ref. 29 was lower in $\gamma$-oryzanol content, whereas the same range of $\gamma$-oryzanol was reported in Ref. 4. This might be the effect of the place and the method of cultivation. Most of the research studies determined antioxidant activity via the DPPH assay. D had the same level of $\mathrm{IC}_{50}$ as Khoa Pathum Thani $60^{29}$; however, it was cultivated using less water than MA. The DK variety exhibited the highest level of antioxidant activity.

The above information reveals that the three varieties with the highest content of $\gamma$-oryzanol and antioxidant activity were $\mathrm{KN}$, DK, and D. These three 
Table 4 Antioxidant compositions of rice bran extracts with various rice sources and extraction conditions.

\begin{tabular}{|c|c|c|c|c|c|c|c|c|}
\hline Bran varieties & $\gamma$-Oryzanol & $\gamma$-Tocopherol & TPC & TFC & $\mathrm{IC}_{50} \mathrm{DPPH}$ & ABTS & FRAP & Remark \\
\hline Japonica type, Seoul, Korea & & & $6.5 \pm 0.4$ & & & $16 \mu \mathrm{M}$ & 0.022 & Ref. 31 \\
\hline Phitsanulok 2, Chiang Rai rice & & & 0.7 & & & & & Ref. 14 \\
\hline Suphan Buri 1, Chiang Rai rice & & & $1.0 \pm 0.0$ & & & & & \\
\hline Pa tong 1 , Chiang Rai rice & & & $0.9 \pm 0.1$ & & 0.05 & 0.02 & & \\
\hline Sangyod Phatthalung rice & 0.67 & & $0.4 \pm 0.3$ & $0.30^{+}$ & $35 \%$ & & & Ref. 34 \\
\hline Fajr, Babolsar, Iran & & & 3.3 & & $93 \%$ & & & Ref. 24 \\
\hline Tarem, Babolsar, Iran & & & 2.0 & & $90 \%$ & & & \\
\hline MA 105, Roi-Et province & 5.38 & 4.74 & $2.7 \pm 0.3$ & & $86 \%$ & & 0.032 & Ref. 4 \\
\hline (TK9), Japonica & 1.78 & 0.10 & $1.2-2.5$ & & & & & Ref. 35 \\
\hline MA 105, Thailand & 0.99 & 0.10 & 2.9 & 0.08 & 0.52 & & $0.14\left(\mathrm{IC}_{50}\right)$ & Ref. 29 \\
\hline Khoa Pathum Thani 60, & 1.08 & 0.13 & 3.2 & 0.06 & 0.38 & & $0.11\left(\mathrm{IC}_{50}\right)$ & \\
\hline Khao Suphan buri 90 & 0.56 & 0.12 & 2.8 & 0.03 & 0.58 & & $0.31\left(\mathrm{IC}_{50}\right)$ & \\
\hline Khao Chinat 1 & 0.79 & 0.06 & 2.2 & 0.10 & 0.74 & & $0.55\left(\mathrm{IC}_{50}\right)$ & \\
\hline Khao Gokho 13 & 0.61 & 0.08 & 2.7 & 0.09 & 0.64 & & $0.45\left(\mathrm{IC}_{50}\right)$ & \\
\hline Venezuelan & & & $1.1-1.2$ & & & & & Ref. 9 \\
\hline Pakistan rice bran & & & $2.5-3.6$ & & & & & Ref. 22 \\
\hline Pigment rice bran extract & & & $8-45$ & & & & & Ref. 33 \\
\hline
\end{tabular}

${ }^{\dagger}$ Units: $\gamma$-Oryzanol, $\gamma$-Tocopherol (mg/g DW); TPC (mg GAE/g DW); TFC (mg QE/g DW); IC ${ }_{50}$ DPPH (mg/ml); ABTS (mg TEAC/g DW); FRAP ( $\left.\mathrm{mM} \mathrm{FeSO}_{4} / \mathrm{g} \mathrm{DW}\right)$.

* mg CE/g DW.

varieties need to be further evaluated for their neuronal viability, neuroprotective, and neuritogenic abilities.

\section{Neuronal viability assay}

Neither the extracts (KN, DK and D) nor the $\gamma$ oryzanol standard caused neurotoxicity in the P19 neuronal cells $\left(\mathrm{IC}_{50}\right.$ more than $\left.10 \mu \mathrm{g} / \mathrm{ml}\right)$. The cell viabilities percentages of the cultured neurons treated with DK and $\gamma$-oryzanol at $100 \mathrm{ng} / \mathrm{ml}$ concentration were $156.0 \pm 5.7$ and $131 \pm 13 \%$, and the cell viabilities for $\mathrm{KN}$ at $10 \mathrm{ng} / \mathrm{ml}$ and $\mathrm{D}$ at $1 \mathrm{ng} / \mathrm{ml}$ were $124 \pm 13$ and $118.9 \pm 5 \%$, respectively. These results suggest that all the extracts and $\gamma$-oryzanol had high cell viabilities (over 100\%); they enhanced survival of the cultured neurons. Hence their effective concentrations (very low concentrations) were selected for studying their neuroprotective abilities via the serum deprivation method and neuritogenicity.

\section{Neuroprotective and neuritogenic assays}

Neuroprotective assay is used to evaluate the ability of an antioxidant against oxidative stress and inducing cell death triggered by serum deprivation. The neuroprotective abilities of these extracts were evaluated and treated with different conditions (Table 5). The average cell ability percentage of all the extracts ranged from 40.6-60.0\%, compared
Table 5 Neuroprotective abilities; the average percentage of cell viability by serum deprivation from various treatments.

\begin{tabular}{lc}
\hline Compound & Cell viability (\%) \\
\hline$\gamma$-Oryzanol $(100 \mathrm{ng} / \mathrm{ml})$ & $60.2 \pm 9.1^{*}$ \\
$\mathrm{DK}(100 \mathrm{ng} / \mathrm{ml})$ & $40.6 \pm 9.5$ \\
$\mathrm{D}(1 \mathrm{ng} / \mathrm{ml})$ & $54.9 \pm 11.5^{*}$ \\
$\mathrm{KN}(10 \mathrm{ng} / \mathrm{ml})$ & $43.1 \pm 10.9$ \\
Quercetin $(1 \mathrm{nM})$ & $58.0 \pm 9.2^{*}$ \\
$\alpha$-MEM $+10 \mu \mathrm{M}$ Ara-C + 0.5\% DMSO & $16.3 \pm 4.5$ \\
$\alpha$-MEM $+10 \mu \mathrm{M}$ Ara-C & $16.6 \pm 4.7$ \\
P19SM + 10 $\mu \mathrm{M}$ Ara-C + 0.5\% DMSO & $100.3 \pm 0.3$ \\
P19SM + 10 $\mu$ M Ara-C & $100.0 \pm 0.0$ \\
\hline
\end{tabular}

* $p<0.05$ compared with toxic condition ( $\alpha$-MEM + $10 \mu \mathrm{M}$ Ara-C) and solvent control of toxic condition $(\alpha-\mathrm{MEM}+10 \mu \mathrm{M}$ Ara-C + 0.5\% DMSO). P19SM composed of $\alpha-\mathrm{MEM}+10 \%$ FBS. All media were added $1 \% \mathrm{v} / \mathrm{v}$ antibiotic-antimycotic solution.

to that of the control. D was the only variety that demonstrated resistance to a toxic condition and to the solvent control of a toxic condition at 95\% significant level. The highest percentage of cellular viability was found in the $\gamma$-oryzanol standard; however, it was not significantly different. Furthermore, the extracts were not significantly different in their average cellular viabilities when compared to the positive control, quercetin, which is a well-known antioxidant and antioxidative 
Table 6 The neuritogenicity of the extracts.

\begin{tabular}{lcc}
\hline Compound & Neurites & Length $(\mu \mathrm{m})$ \\
\hline$\gamma$-Oryzanol $(100 \mathrm{ng} / \mathrm{ml})$ & $2.57 \pm 0.23^{*, * * *}$ & $49.9 \pm 6.0^{* * *}$ \\
DK $(100 \mathrm{ng} / \mathrm{ml})$ & $2.53 \pm 0.23^{*, * * *}$ & $50.4 \pm 5.4^{* *}$ \\
$\mathrm{D}(1 \mathrm{ng} / \mathrm{ml})$ & $2.70 \pm 0.23^{* *}$ & $29.8 \pm 1.9^{* * *}$ \\
KN $(10 \mathrm{ng} / \mathrm{ml})$ & $3.30 \pm 0.24^{* *}$ & $45.1 \pm 3.4^{* * *}$ \\
Quercetin $(1 \mathrm{nM})$ & $3.67 \pm 0.28^{* *}$ & $71.5 \pm 8.1^{*}$ \\
P19SM + 10 $\mu \mathrm{M}$ Ara-C & $1.23 \pm 0.08$ & $39.2 \pm 4.7$ \\
$\quad+0.5 \%$ DMSO & & $32.9 \pm 3.9$ \\
P19SM + 10 $\mu$ M Ara-C & $1.40 \pm 0.11$ & 3 \\
\hline
\end{tabular}

$* p<0.05$ compared with solvent control, P19SM + $10 \mu \mathrm{M}$ Ara-C + 0.5\% DMSO; ** $p<0.05$ compared with positive control, quercetin. P19SM composed of $\alpha$-MEM+ $10 \%$ FBS. All media were added 1\% v/v antibiotic-antimycotic solution.

stress compound ${ }^{10}$. These studies suggested that $\mathrm{D}$ possesses significant neuroprotective ability among these extracts, and this ability might arise from other components found in the D extract, rather than $\gamma$ oryzanol, which can be used as a natural source of nutrient-rich content. According to the antioxidant and neuroprotective abilities of rice bran extracts, it is possible that the neuroprotective activity of these extracts might not be derived simply from the antioxidative process.

Neuritogenic assays were used to measure the length of neurite outgrowth per cell. The method is commonly used to assess the ability of a compound that affects the growth of neurites. All the oil extracts were found to exhibit neuritogenic ability by increasing the number of neurites (Table 6). KN, D, DK had greater numbers of neurites than the solvent control at 95\% significant level and were not significantly different compared to that of the $\gamma$-oryzanol standard. However, the extract did not have the ability to increase the length of the neurites when compared to quercetin, the positive control. The results of phase-contrast micrographs of cultured P19-derived neurons were shown in Fig. 1. $\mathrm{KN}$ had the greatest impact in increasing the number of neurites according to the result that used a lower concentration to increase the number of neurites, as compared to DK. These observations may be due to the presence of other compounds in the extracts that can also increase the number of neurites, even though $\gamma$-oryzanol was found to be low in $\mathrm{KN}$.

\section{CONCLUSIONS}

This study examined a new variety of rice that uses less water for cultivation as compared to the conventional variety (Khao Dowk Mali 105). The new variety, commonly called upland rice bran, has been evaluated for its oil and chemical content, as well as antioxidant activity. The upland rice bran colour changes from red to brown possibly reflecting the bioactive compounds it contains; the yellow from $\gamma$-oryzanol. The neuroprotective and neuritogenic effects of such extracts were also examined in the Dok-kham, Dok-kha and varieties, which have high bioactive compound contents and antioxidant capabilities. Among these extracts, Dokkha was found to possess significant neuroprotective ability. This ability might arise from other components found in the Dok-kha extract other than $\gamma$-oryzanol, and could be used as a new natural source of nutrient-rich content. Khem-ngen and Dok-kha have other compounds, in addition to $\gamma$ oryzanol, such as colour pigments that can also promote growth and the number of neurites. All the extracts and $\gamma$-oryzanol exhibited neuritogenic abilities by promoting increases in the number of neurites, thus having the potential for dietary use in the form of upland rice bran oil.

Acknowledgements: This study has been supported by research funds with Grant number KREF025603 from King Mongkut's Institute of Technology Ladkrabang.

\section{REFERENCES}

1. Petchseechoung W (2016) Rice Industry, Thailand Outlook 2016-2018, Krungsri Research, 1-5.

2. Zigoneanu IG, Williams L, Xu Z, Sabliov CM (2008) Determination of antioxidant components in rice bran oil extracted by microwave assisted method. Bioresour Technol 99, 4910-8.

3. Khuwijitjaru P, Yuenyong $\mathrm{T}$, Pongsawatmanit $\mathrm{R}$, Adachi S (2009) Degradation kinetics of gammaoryzanol in antioxidant-stripped rice bran oil during thermal oxidation. J Oleo Sci 58, 491-7.

4. Butsat S, Siriamornpun S (2010) Antioxidant capacities \& phenolic compounds of the husk, bran and endosperm of Thai rice. Food Chem 119, 606-13.

5. Chia SL, Boo HC, Muhamad K, Sulaiman R, Umanan F, Chong GH (2015) Effect of subcritical carbon dioxide extraction and bran stabilization methods on rice bran oil. J Am Oil Chem Soc 92, 393-402.

6. Xu Z, Godber JS (2001) Antioxidant activities of major components of $\gamma$-oryzanol from rice bran using a linoleic acid model. $J$ Am Oil Chem Soc 78, 645-9.

7. Regan H (2015) Thailand is Suffering from the Worst Drought in Decades, TIME Online Newsletters.

8. Nokkoul R (2015) Upland Rice: Agricultural Product for Economic and Social Development, Department of Agricultural Technology, KMITL PCC, Thailand. (in Thai) 

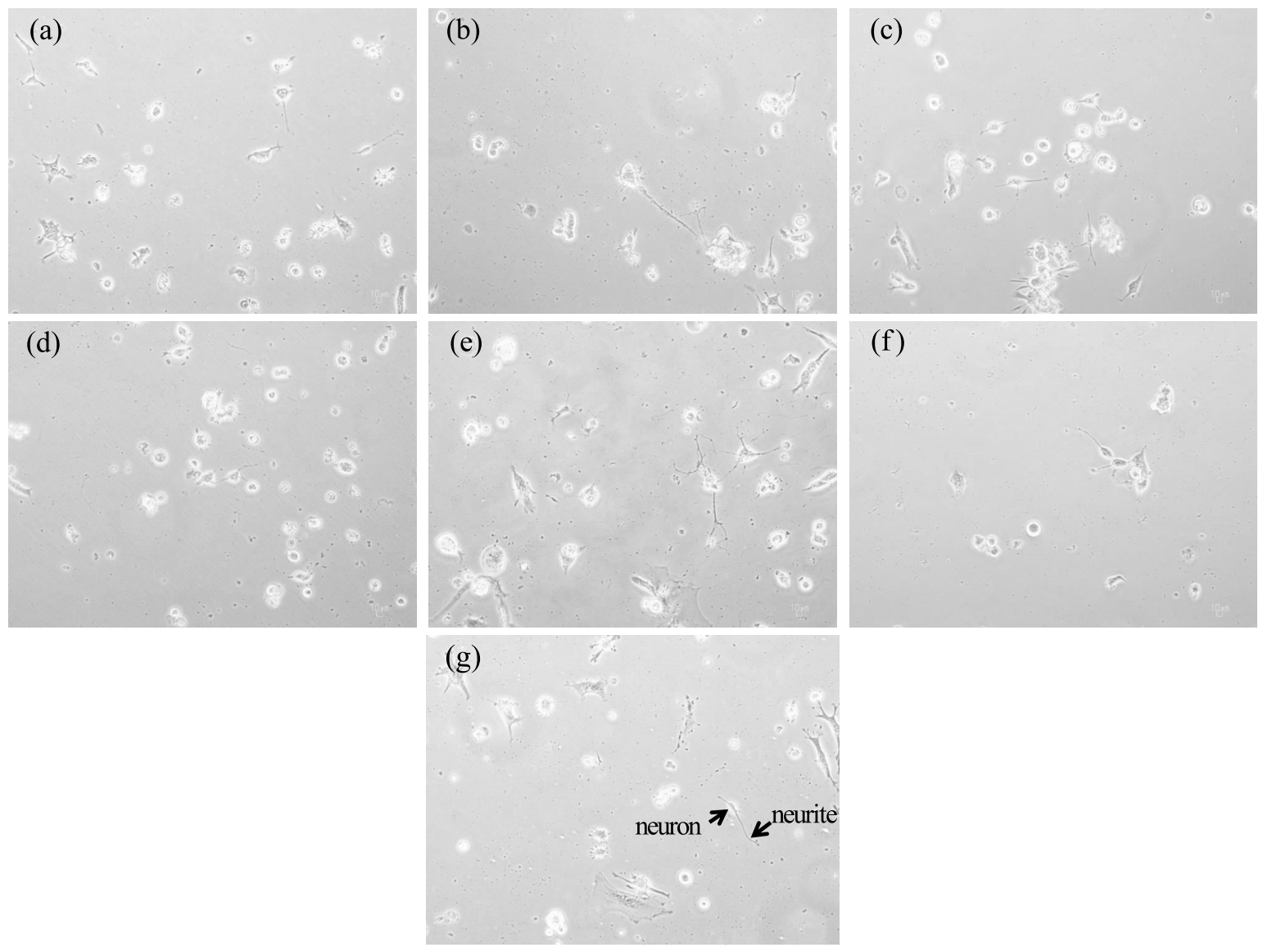

Fig. 1 The neuritogenicity of extracted oil in a P19-derived neuron culture. Phase-contrast micrographs of cultured P19-derived neurons treated with: (a) $100 \mathrm{ng} / \mathrm{ml}$ of $\gamma$-oryzanol, (b) $100 \mathrm{ng} / \mathrm{ml}$ of DK, (c) $1 \mathrm{ng} / \mathrm{ml} \mathrm{of} \mathrm{D;} 10 \mathrm{ng} / \mathrm{ml} \mathrm{of}$ $\mathrm{KN}$, (d) $1 \mathrm{nM}$ quercetin, (f) $0.5 \% \mathrm{DMSO}$, and (g) control.

9. Aguilar-Garcia C, Gavino G, Baragaño-Mosqueda MB, Hevia P, Gavino VC (2007) Correlation of tocopherol, tocotrienol, $\gamma$-oryzanol and total polyphenol content in rice bran with different antioxidant capacity assays. Food Chem 102, 1228-32.

10. Tangsaengvit N, Kitphati W, Tadtong S, Bunyapraphatsara N, Nukoolkarn V (2013) Neurite outgrowth and neuroprotective effects of quercetin from Caesalpinia mimosoides Lamk. on cultured P19derived neurons. Evid Based Complement Alternat Med 838051, 1-7.

11. Hwang SJ, Yoon WB, Lee OH, Cha SJ, Kim JD (2014) Radical-scavenging-linked antioxidant activities of extracts from black chokeberry and blueberry cultivated in Korea. Food Chem 146, 71-7.

12. Shao YF, Xu FF, Sun X, Bao JS, Beta $T$ (2014) Identification and quantification of phenolic acids and anthocyanins as antioxidants in bran, embryo and endosperm of white, red and black rice kernels (Oryza sativa L.). J Cereal Sci 59, 211-8.

13. Povilaitis D, Šulniūtè V, Rimantas Venskutonis RP,
Kraujalienè V (2015) Antioxidant properties of wheat and rye bran extracts obtained by pressurized liquid extraction with different solvents. $J$ Cereal Sci 62, 117-23.

14. Kanlayavattanakul M, Lourith N, Tadtong S, Jongrungruangchok S (2015) Rice panicles: New promising unconventional cereal product for health benefits. J Cereal Sci 66, 10-7.

15. Bao JS, Cai Y, Sun M, Wang GY, Corke H (2005) Anthocyanins, flavonoids, and free radical scavenging activity of Chinese bayberry (Myrica rubra) extracts and their colour properties and stability. J Agric Food Chem 53, 2327-32.

16. Shen Y, Jin L, Xiao P, Lu Y, Bao J (2009) Total phenolics, flavonoids, antioxidant capacity in rice grain and their relations to grain color, size and weight. $J$ Cereal Sci 49, 106-11.

17. Tadtong S, Kanlayavattanakul M, Lourith N (2013) Neuritogenic and neuroprotective activities of fruit Residues. Nat Prod Commun 8, 1583-6.

18. AOAC (2012) Official Methods of Analysis, 19th edn, 
Association of Official Analytical Chemists, Washington, DC.

19. ASEANFOODS (2011) Asean Manual of Food Analysis, 1st edn, Regional Center of Asean Network of Food Data System, Institute of Nutrient, Mahidol University, Thailand.

20. Ruen-Ngam D, Thawai C, Nokkoul R, Sukonthamut $S$ (2014) Gamma-oryzanol extraction from upland rice bran. Int J Biosci Biochem Bioinforma 4, 252-5.

21. Liu Q, Yao H (2007) Antioxidant activities of barley seeds extracts. Food Chem 102, 732-7.

22. Lqbal S, Younas U, Sirajuddin, Chan WK, Sarfraz RA, Uddin KM (2012) Proximate composition and antioxidant potential of leaves from three varieties of Mulberry (Morus sp.): a comparative study. Int $J$ Mol Sci 13, 6651-64.

23. Iacovitti L, Stull ND, Johnston K (1997) Melatonin rescue dopamine neurons from cell death in tissue culture models of oxidative stress. Brain Res 768, 317-26.

24. Arab F, Alemzadeh I, Maghsoudi V (2011) Determination of antioxidant component and activity of rice bran extract. Sci Iran 18, 1402-6.

25. Chen M, McClung AM, Bergman CJ (2016) Concentrations of oligomers and polymers of proanthocyanidins in red and purple rice bran and their relationships to total phenolics, flavonoids, antioxidant capacity and whole grain color. Food Chem 208, 279-87.

26. Vasishtha H, Srivastava PR (2013) Effect of soaking and cooking on dietary fibre components of different type of chickpea genotypes. J Food Sci Technol 50, 579-84.

27. Özkaya H, Özkaya B, Duman B, Turksoy S (2017) Effect of dephytinization by fermentation and hydrothermal autoclaving treatments on the antioxidant activity, dietary fiber, and phenolic content of oat bran. J Agric Food Chem 65, 5713-9.

28. Chaiteerapattarapong S (2016) Evaluation of gamma-oryzanol in Khao Dawk Mali 105 and Dawk Pa-yawm upland rice brans, Master thesis, KMITL, Thailand.

29. Chotimarkorn C, Ushio H (2008) The effect of transferulic acid and gamma-oryzanol on ethanol-induced liver injury in C57BL mouse. Phytomedicine 15, 951-8.

30. Chakuton K, Puangpronpitag D, Nakornriab M (2012) Phytochemical content and antioxidant activity of colored and non-colored Thai rice cultivars. Asian J Plant Sci 11, 285-93.

31. Kim S, Lim S (2016) Enhanced antioxidant activity of rice bran extract by carbohydrase treatment. $J$ Cereal Sci 68, 116-21.

32. Premakumara GAS, Abeysekera WKSM, Ratnasooriya WD, Chandrasekharan NV, Bentota AP (2013) Antioxidant, anti-amylase and anti-glycation potential of brans of some Sri Lankan traditional and improved rice (Oryza sativa L.) varieties. J Cereal Sci 58, 451-6.

33. Goffman FD, Berman CJ (2004) Rice kernel phenolic content and its relationship with antiradical efficientcy. $J$ Sci Food Agric 84, 1235-40.

34. Thanonkaew A, Wongyai S, McClements DJ, Decker EA (2012) Effect of stabilization of rice bran by domestic heating on mechanical extraction yield, quality, and antioxidant properties of cold-pressed rice bran oil (Oryza saltiva L.). LWT-Food Sci Technol 48, 231-6.

35. Lai P, Li KL, Lu S, Chen HH (2009) Phytochemicals and antioxidant properties of solvent extracts from Japonica rice bran. Food Chem 117, 538-44.

36. Sae-ang V (2016) Extraction and antioxidant activity evaluation of upland rice bran oil for cosmetic product applications. Master thesis, KMITL, Thailand. 